\title{
Improvement in performance of a reservoir system with carry over storages
}

\author{
M.Visweswararao ${ }^{1}$, G.K. Viswanadh ${ }^{2}$ \\ 1. Professor of civil engineering, malla reddy institute of technology, hyderabad \\ 2. Professor of civil engineering department, jntuh, hyderabad gkviswanadh@gmail.com
}

\begin{abstract}
Carry-over storages are over-year storages and will be able to hold flows more than the yearly requirement whereas with-in year storages are provided to take care of seasonal variations of flows. When there are insufficient flows in the initial period the carry over storages will help in meeting the demands of this period as the flows from the previous year are stored in the reservoirs. They will also be helpful in improving the system performance by meeting the demands in deficit years with the carried forward flows. Srisailam and Nagarjunasagar reservoirs in Krishna basin are provided as carry over storages. In this study an effort is made to study the effect of carry-over storages of Srisailam and Nagarjunasagar on the performance of the system of reservoirs Srisailam, Nagarjunasagar and Krishna delta of the Krishna system. The study concluded that the success rates of irrigation at Srisailam, Nagarjunasagar and Krishna delta have improved with carry over storages. The improvement is marginal at Srisailam but more than 13\% for Nagarjunasagar and Prakasam Barrage.
\end{abstract}

Key Words: Carry-over storage, Irrigation demands, Srisailam, Nagarjunasagar, Prakasam Barrage

\section{I.INTRODUCTION}

The River Krishna rises in the Mahadev range of the Western Ghats near Mahabaleshwar at an altitude of $1337 \mathrm{~m}$ above sea level and flows through Maharashtra, Karnataka and Andhra Pradesh gathering water on its way from innumerable rivers, streams or tributaries and drops into the Bay of Bengal. River Bhima and Tungabhadra are major tributaries of river Krishna. Main Krishna, Bhima and Tungabhadra constitute the stems of the river Krishna. Jurala,Srisailam, Nagarjunasagar, Krishna delta are the major projects on main Krishna. The srisailam reservoir complex of Srisailam, Nagarjunasagar and Krishna delta has to cater to the needs of Srisailam irrigation of 19 TMC for SRBC, 33 TMC of evaporation losses in Srisailam, 280 TMC for irrigation and 16.5 TMC of drinking water to Hyderabad city at Nagarjunasagar,152.2 TMC at Prakasam Barrage (Krishna delta) at $75 \%$ dependability. In this study the TGP project for irrigation of $25 \mathrm{TMC}$ at lower dependability is also considered.

\section{II.LITERATURE SURVEY}

The aim of the study by Jean christopher et.al was to assess the performance of two irrigated schemes in the upper Volta basin one in Burkhana and other in Ghana, through participatory methods to identify constraints and to discuss possible solutions. If the optimal crop management, proper maintenance of the system, marketing facilities are provided then there will be lot of improvement in agricultural production and economic returns and in overall performance of the reservoirs.(Water resources and rural development, November,2015, Jean-Chrisphor pousin et.al)

A monthly time stepped simulation model has been developed and applied for evaluating the performance of the UKAI reservoir in Gujarat. Standard operating policy was considered for operation. The constriction on reservoir maximum levels and sedimentation are considered. The system behaviour is further investigated for reliability resilence, vulnerability and sustainability. The simulated releases are compared to the actual releases and it is observed that the system has fewer deficits but more spills.(Conference paper in HYDRO 2014 International , Bhopal)

The performance and productivity of two small reservoirs was investigated by Joshua et al. In the two systems considered there is lot of variability in the availability of water. In one system more water is available resulting in relaxation of management and inefficient irrigation for Tanga system where as in other system there is shortage of water for Weega system. The comparisons indicated better management practices will yield improvement in both the systems.(Irrigation and drainage, 2008, Joshua W. Faulkner et.al)

JOG-yaon park et.al studied the means to improve the current reservoir simulation module of SWAT for simulating multiple water supply system of agriculture based and reservoir based operating rules. For this purpose auto irrigation is simulated by coupling SWAT and IWRM (Irrigation water requirement model) applying RWL(restricted water level) component operation rules and considering return flows. It was concluded that the combination of IWRM and SWAT provides for a good reference to understand the variations of Agricultural water resources and is expected to support the assessment of multiple water supply capacity. (International SWAT conference,2013, Jog-Yoon-Park et.al)

\section{METHODOLOGY FOR THE PRESENT STUDY}

In the present study the inflows are worked out at Srisailam, Srisailam to Nagarjunasagar, Nagarjunasagar to Prakasam barrage and the total inflows are compared with the demands planned on yearly basis and the success 
or failure of meeting the demands on annual basis is worked out.

The salient features of Srisailam and Nagarjunasagar reservoirs are shown in Table. 1

\begin{tabular}{|c|c|r|r|}
\hline \multicolumn{3}{|c|}{ Table-l: The salient features of srisailam and } \\
nagariumasagar in krishna basin
\end{tabular}

The annual demands of the projects below Srisailam are given below in Table- 2

In the $1^{\text {st }}$ scenario, these annual demands are compared with annual flows at each project and the success rates are worked out on annual basis. It is assumed that with- in -year storages are provided and whenever flows are available in a given year more than the demands they will be met. This will give an idea about the success without carry over storages.

In the $2^{\text {nd }}$ scenario the integrated operation of the system Srisailam, Nagarjunasagar and Prakasam barrage is done considering the storages of Srisailam and Nagarjunasagar which are carry over storages and the success rates of each component demand is worked out. Both the results are compared and the conclusions are drawn.

For the purpose of integrated operation,the annual flows are broken in to monthly flows considering the gauge flow data or reservoir data. The monthly flows are routed through the Srisailam reservoir considering the planned utilisations of that project. The spills from Srisailam and the intermediate gross flows less the minor irrigation and the small projects in the catchment between Srisailam to
Nagarjunasagar form the inflows in Nagarjunasagar. These flows are again routed considering the planned utilisations of Nagarjunasagar reservoir to Prakasam Barrage. The reservoir operation is done in monthly timesteps. Success rates of meeting the annual demand at each reservoir are worked out by comparing demand planned and met for all demands

Table-2 demands under various projects

\begin{tabular}{|l|l|l|}
\hline Shno & \multicolumn{1}{|c|}{ Description } & $\begin{array}{l}\text { Demand in } \\
\text { TMC }\end{array}$ \\
\hline 1 & SRISAILAM Project(SLM) & \\
\hline & Chennai water sybply(CWS) & 15 \\
\hline & $\begin{array}{l}\text { Srisailam right branch } \\
\text { canal(SRBC) }\end{array}$ & 19 \\
\hline & Evaporation & 33 \\
\hline & $\begin{array}{l}\text { TGP(only when flow in } \\
\text { Krishna is >2293) }\end{array}$ & 25 \\
\hline 2 & $\begin{array}{l}\text { NAGARJNASAGAR(NSP) } \\
\text { project }\end{array}$ & 16.5 \\
\hline & HWS & 264 \\
\hline & Imigation & 17 \\
\hline 3 & Evaporation & PRAKASAM Barrage(PB) \\
\hline & Imigation for Krishna delta & 152.2 \\
\hline &
\end{tabular}

IV. RESULTS AND DISCUSSIONS

The comparative results year wise for both the scenarios is presented in Table 3. The demands, met without carryover and met with carryover for Srisailam, Nagarjunasagar and Prakasam Barrage are also shown in fig1 to Fig 3. 


\begin{tabular}{|c|c|c|c|c|c|c|c|c|c|}
\hline \multicolumn{10}{|c|}{ statement showing the demannos metwith and without carry vore sororges } \\
\hline & & & & & & & & & \\
\hline \multirow[b]{2}{*}{ Year } & \multicolumn{3}{|c|}{ Sisialam } & \multicolumn{3}{|c|}{ Nagarjunassgar } & \multicolumn{3}{|c|}{ Praksambarrage } \\
\hline & demand & $\begin{array}{l}\text { demand } \\
\text { met } \\
\text { without } \\
\text { carnover }\end{array}$ & $\begin{array}{l}\text { demand } \\
\text { met with } \\
\text { carryover }\end{array}$ & demand & \begin{tabular}{|l|} 
demand \\
met \\
without \\
Carryover \\
\end{tabular} & $\begin{array}{l}\text { demand } \\
\text { metwith } \\
\text { carryover }\end{array}$ & demand & \begin{tabular}{|l|} 
demand \\
met \\
without \\
carryover \\
\end{tabular} & $\begin{array}{l}\text { demand } \\
\text { met with } \\
\text { Carryover }\end{array}$ \\
\hline 19601 & 9 & & 920 & 297. & $\begin{array}{ll}7.5 & 297.5 \\
\end{array}$ & 297.5 & 152.2 & 152.2 & 152.2 \\
\hline 1902 & $\bar{g}$ & g & 920 & 297. & $\begin{array}{ll}7.5 & 297.5 \\
\end{array}$ & 297.5 & 152.2 & 152.2 & 152.2 \\
\hline 1963 & $\frac{9}{9}$ & 9 & 920 & 297. & $\begin{array}{ll}7.5 & 297.5 \\
\end{array}$ & 297.55 & 152.2 & 152.2 & 152.2 \\
\hline $\mid 1964$ & 9 & 9 & 920 & 297. & $\begin{array}{ll}7.5 & 297.5 \\
\end{array}$ & 207.5 & 152.2 & 152.2 & 152.2 \\
\hline 1965 & 6 & 6 & 67.0 & 297. & 7.5273 .559 & 297.5 & 152.2 & 69.35 & 152.2 \\
\hline 19606 & 6 & 6 & 67.0 & 297. & $\begin{array}{cc}7.5 & 186.1579 \\
\end{array}$ & 261.09 & 152.2 & 58.45 & 149.26 \\
\hline 1967] & 9 & 79.5 & 79.5 & 297. & $\begin{array}{ll}7.5 & 273.8\end{array}$ & 20078 & 152.2 & 139.92 & 139.92 \\
\hline 1968 & 6 & 6 & 67.0 & 297. & \begin{tabular}{l|l}
7.527 .3880 \\
\end{tabular} & 297.5 & 152.2 & 69.8 & 152.2 \\
\hline 1969 & 9 & 9 & 920 & 297. & \begin{tabular}{ll|}
7.5 & 297.5 \\
\end{tabular} & 297.5 & 152.2 & 152.2 & 152.2 \\
\hline 1970 & 9 & 9 & 920 & 297. & \begin{tabular}{|l|l}
7.5 & 297.5 \\
\end{tabular} & 297.5 & 152.2 & 152.2 & 152.2 \\
\hline $\mid 1971$ & 6 & 6 & 67.0 & 297. & $\begin{array}{ll}7.5 & 297.5 \\
\end{array}$ & 297,55 & 152.2 & \begin{tabular}{|c|}
97.3 \\
\end{tabular} & 152.2 \\
\hline 1972 & 6 & 31.9 & 43.9 & 297. & 7.514 .92885 & 88.9 & 152.2 & 20 & 97,25 \\
\hline 1973 & 9 & 9 & 920 & 297. & $\begin{array}{ll}7.5 & 20073\end{array}$ & 200,73 & 1522 & \begin{tabular}{|l|l|}
2 & 133.24 \\
\end{tabular} & 133.24 \\
\hline $\mid 1974$ & $\bar{g}$ & 9 & 920 & 297. & \begin{tabular}{|l|l}
7.5 & 297.5 \\
\end{tabular} & 207.5 & 152.2 & 152.2 & 152.2 \\
\hline 1975 & 9 & 9 & 920 & 297. & \begin{tabular}{c|c|}
7.5 & 297.5 \\
\end{tabular} & 297.55 & 152.2 & 152.2 & 152.2 \\
\hline 1976 & 9 & 9 & 920 & 297. & $\begin{array}{ll}7.5 & 297.5 \\
\end{array}$ & 297.5 & 152.2 & 152.2 & 152.2 \\
\hline 1977| & 9 & 9 & 920 & 297. & \begin{tabular}{|l|l|}
7.5 & 297.5 \\
\end{tabular} & 297.5 & 152.2 & $2 \mid 104.2212$ & 152.2 \\
\hline 1978 & 9 & 9 & 920 & 297. & $\begin{array}{ll}7.5 & 297.5 \\
\end{array}$ & 297.5 & 152.2 & 152.2 & 152.2 \\
\hline 1979 & 9 & 9 & 920 & 297. & $\begin{array}{ll}7.5 & 297.5 \\
\end{array}$ & 297,55 & 152.2 & 152.2 & 152.2 \\
\hline 1980 & 9 & 9 & 920 & 297. & $\begin{array}{ll}7.5 & 297.5 \\
\end{array}$ & 297.5 & 152.2 & 152.2 & 152.2 \\
\hline 1981 & $\frac{9}{9}$ & $\frac{9}{9}$ & 920 & 297. & \begin{tabular}{|l|l|}
7.5 & 297.5 \\
\end{tabular} & 297.5 & 152.2 & 152.2 & 152.2 \\
\hline 1982 & 6 & 6 & 67.0 & 297. & $\begin{array}{ll}775 & 2975\end{array}$ & 207.5 & 1522 & 2) 1335.5719 & 1522 \\
\hline 1983 & $\bar{g}$ & 9 & 920 & 297. & $\begin{array}{ll}7.5 & 297.5 \\
\end{array}$ & 297.55 & 152.2 & 2152.2 & 152.2 \\
\hline 1984 & $\frac{6}{6}$ & 6 & 67.0 & 297. & \begin{tabular}{c|c|}
7.5 & 297.5 \\
\end{tabular} & 297.5 & 152.2 & 259.50307 & 152.2 \\
\hline 1985 & 6 & 38. & 38.7 & & 7.5888 .85140 & 13669 & 152.2 & 69.75 & 128.85 \\
\hline 1986 & 6 & 38. & 38.7 & & \begin{tabular}{|l|l|l|l}
7 & 108.4067
\end{tabular} & 115.5 & 152.2 & 62.45 & 87.94 \\
\hline 1987| & 6 & 3 & 3 & 297. & $\begin{array}{ll}7.52688302 \\
\end{array}$ & 50.25 & 152.2 & 45.35 & 56.6 \\
\hline 1988 & $\bar{g}$ & 83. & 83.77 & 297. & $\begin{array}{lll}7.5 & 290\end{array}$ & 205599 & 152.2 & $\mid 147.3$ & 147.26 \\
\hline 1989 & $\bar{g}$ & 9 & 920 & 297. & 7.5238 .7823 & 297.5 & 152.2 & 152.2 & 152.2 \\
\hline 1990 & 9 & g & 920 & 297. & $\begin{array}{ll}7.5 & 297.5 \\
\end{array}$ & 297.5 & 152.2 & 149.3 & 149.31 \\
\hline $\mid 991$ & 9 & 9 & 920 & 297. & $\begin{array}{ll}7.5 & 2975\end{array}$ & 297.55 & 152.2 & 152.2 & 152.2 \\
\hline 1992 & 6 & 6 & 67.0 & 297. & $\begin{array}{ll}7.5 & 286.872\end{array}$ & 297.19 & 152.2 & 35.1 & 147,13 \\
\hline 1993 & 9 & 79. & 79.5 & 297. & $\begin{array}{ll}7.5 & 290.7\end{array}$ & 200,73 & 152.2 & $|31.7|$ & 131.74 \\
\hline 1994 & 9 & 9 & 920 & 297. & $\begin{array}{ll}7.5 & 297.5 \\
\end{array}$ & 297.5 & 152.2 & 152.2 & 152.2 \\
\hline 1905 & $\overline{6}$ & 50 & 50.2 & 297. & \begin{tabular}{l|l}
7.5 & 78.56742
\end{tabular} & 168.5 & 152.2 & 84.45 & 138.54 \\
\hline 1996 & 9 & $\overline{61.1}$ & 61.77 & 297. & $\begin{array}{ll}7.5 & 263.0 \\
\end{array}$ & 26359 & 152.2 & 149.5 & 149.46 \\
\hline $\mid 997$ & $\overline{9}$ & 9 & 920 & 297. & $\begin{array}{ll}7.5 & 297.5 \\
\end{array}$ & 207.5 & 152.2 & 152.2 & 152.2 \\
\hline 1998 & 9 & 79. & 79.5 & 297. & $\begin{array}{ll}7.5 & 297.5 \\
\end{array}$ & 207.5 & 152.2 & 152.2 & 152.2 \\
\hline 1999 & 6 & 6 & 67.0 & 297. & \begin{tabular}{|l|l}
7.5 & 297.5 \\
\end{tabular} & 297.55 & 152.2 & 152.2 & 152.2 \\
\hline 2000 & 6 & 6 & 67.0 & 297. & $\begin{array}{ll}775 & 2975 \\
\end{array}$ & 297.5 & 1522 & $2 \mid 1128598$ & 1522 \\
\hline 2001 & 6 & 43. & 43.2. & & 7.5111 .5677 & 158 & 152.2 & 45.75 & 108.75 \\
\hline 2002 & 6 & 15.9 & 3 & 297. & $\begin{array}{ll}7.5 & 30.61411\end{array}$ & 42.5 & 152.2 & 34.5 & 51.13 \\
\hline 2003 & 6 & & 3 & 297. & 7.5 & 17 & 152.2 & 2.5 & 4.98 \\
\hline 2004 & $\overline{6}$ & $\overline{61 .}$ & 61.77 & 297. & 195.3 & 195529 & 152.2 & 2. 88.90023 & 113.12 \\
\hline 2005 & 9 & 9 & 920 & 297. & $\begin{array}{ll}7.5 & 290.7\end{array}$ & 200.73 & 1522 & $\begin{array}{|ll|}2 & 127.1\end{array}$ & 127.11 \\
\hline 2006 & $\bar{g}$ & $\bar{g}$ & 920 & 297. & \begin{tabular}{|l|l}
7.5 & 297.5 \\
\end{tabular} & 207.5 & 152.2 & 152.2 & 152.2 \\
\hline 2007 & 9 & 2 & 920 & 297. & $\begin{array}{ll}7.5 & 297.5 \\
\end{array}$ & 297.55 & 152.2 & \begin{tabular}{|l|l|}
2 & 152.2 \\
\end{tabular} & 152.2 \\
\hline
\end{tabular}
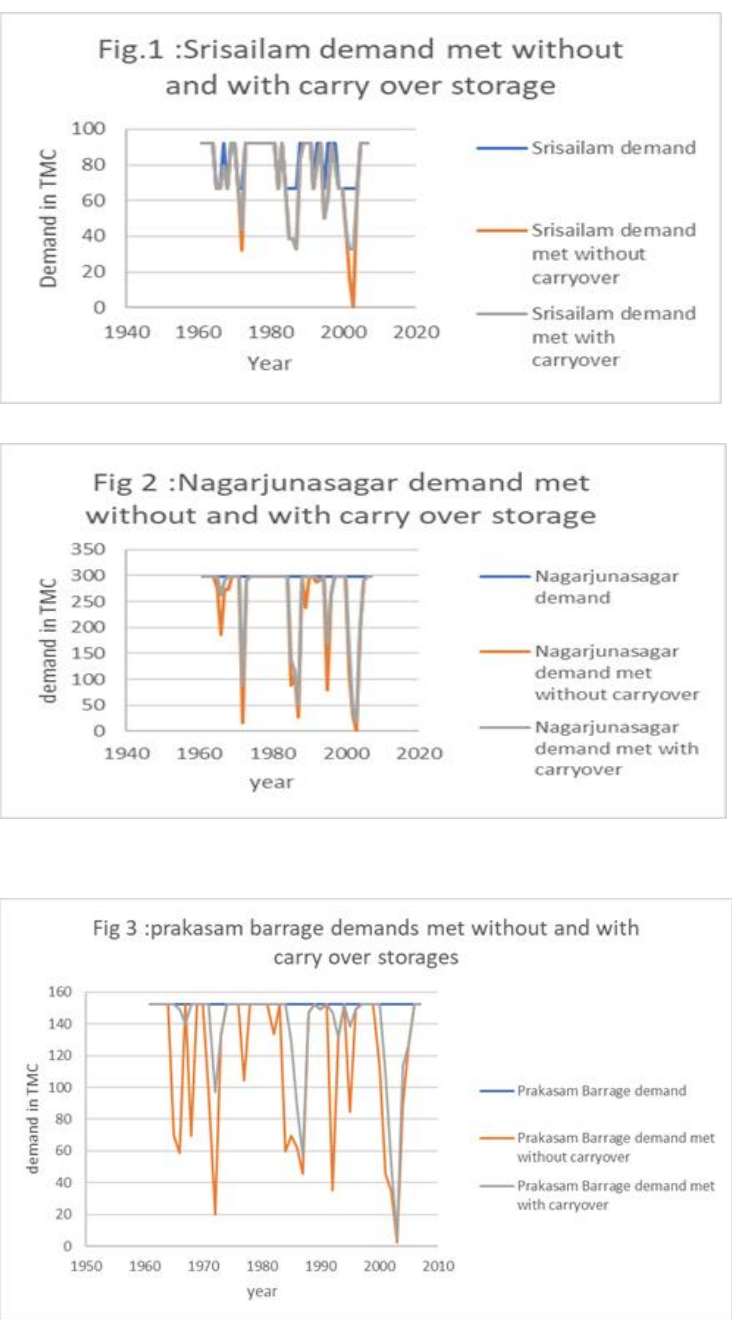

From the above table the success rates of both the scenarios are worked out and presented below

From the above study it could be seen that the SRBC\&MWS demand of 34 TMC is met in $78.7 \%$ of time in both the scenarios. As the quantum of $34 \mathrm{TMC}$ is less compared to inflows there is no necessity of carry over storages for this demand. The SRBC demands can not be met in some years only because the required levels for drawal of SRBC could not be attained.

It could be seen that the demands of Telugu ganga(TGP) which are proposed at Srisailam only when the flows in the entire basin are more than 2293 TMC could be met in $51 \%$ of time in both the scenarios.

The demands of Nagarjunasagar could be met in57.45\% of time where as with carryover storage it could be met in $63.82 \%$ of time showing around $6 \%$ improvement.

The planned demands of Prakasam Barrage could be in $49 \%$ of time without carry over. These demands could be met in $62 \%$ of time with carry over storage showing $13 \%$ improvement.

However it could be seen in deficit years more is met with carry over storages though the deficit is not wiped out completely. For Srisailam the demand met in $1972,2002,2003$ with carry over are 43.95,33,33 compared to $31.94,15.91$ and 0 without carryover. Similarly for NSP and PB the demand met in the deficit years has increased considerably with carry storages. The 
study also proved the carry over storages are not fully useful in consecutive deficit years.

\section{CONCLUSIONS}

From the above study it can be concluded that the carry over storages will improve the system performance during deficit years. It is concluded that the carry over storages of Srisailam and Nagarjuna sagar has improved the performance of almost all projects in the system. It can also be concluding there is lot of reduction in deficits with carryover storages even in years when full demand is not met. It can further be concluded that consecutive deficit years will not be fully taken care by carryover storages. It is also clear that with Pulichintala another reservoir proposed below Nagarjunasagar the system will further improve and the demands of irrigation can be met at near $75 \%$ the required level for irrigation.

\section{REFERENCES}

[1] Jean Christophe Pousin et.al. "performance of small reservoir using iirrigated schemes in the upper volta river basin-case studies in Burkina Faso and Ghana", Water resources and rural development, Nov 2015

[2] Priyank,J. Sarma,Prem Lal Patel,et.al. "performance evaluation of a multi purpose reservoir using simulation models for different scenarios", conference paper at Manit, Bhopal ,2014

[3] Joshua ,.W. Faulkner,et.al. "water use and productivity of two small reservoir irrigation schemes in ghanas upper east region", Irrigation and drainage, Issue 2, Vol 57, pages157163,2008

[4] Park.J,Y,Jog,R.Ha,S.R.Ahn,S.H. Kim and S.J. Kim. "Iimprovement and application of swat model for irrigation water supply in agricultural reservoir of south korea" International swat conference, Toulouse, France,2013

[5] CWC gauge data of Krishna basin

[6] Project reports of Srisailam, SRBC, TGP and Nagarjunasagar

[7] Modernisation report of Krishna delta 